\title{
Onset of Opportunistic Infections in Patients Co-Infected by HTLV-1 and HIV-1, With High CD4+ Cells Count
}

\author{
Catarina Regis, Adriano Oliveira and Carlos Brites \\ Universidade Federal da Bahia, Hospital Universitário Prof. Edgard Santos, Virology Research Laboratory; Salvador, BA, Brazil
}

\begin{abstract}
We reported two cases of patients with coinfection by human immunodeficiency virus (HIV) type 1 and human T-cell lymphotropic virus (HTLV) type I who developed opportunistic infections despite of relatively high CD4 ${ }^{+}$cells count. These cases showed clinical evidence to consider an earlier antiretroviral treatment for coinfected patientes regardless CD4 ${ }^{+}$cells counts.

Key-Words: HIV-1/HTLV-1 co-infection, Opportunistic infections, CD4.
\end{abstract}

Human T-cell lymphotropic virus type I (HTLV-I) is associated with adult T-cell leukemia/lymphoma (ATL), HTLVI-associated myelopathy (HAM/TSP), and typical dermatological and immunological abnormalities. Seroprevalence studies in the USA, Europe and developing countries have demonstrated a high frequency (5-15\%) of HTLV-I coinfection among HIV-1 infected patients [1-3]. These rates are, at least, 100 to 500 higher than that found in general population [1,2]. In Salvador, Bahia (a Northeast Brazilian state), it reaches up to $20 \%[2,3]$.

The interaction between HTLV-I and HIV-1 has generated substantial interest because several laboratory and epidemiologic studies suggested that HTLV infection accelerates the clinical progression of HIV infection. However, the impact of such coinfection on HIV disease is still a controversial subject.

On the other hand, it has been related that HIV-1 could increase the risk or accelerate the expression of HTLV-I related diseases in coinfected individuals, probably due to an increased proviral load. However, other studies have shown that immunosupression per se should be related to expression of such conditions without a rise in HTLV viral load [5-7].

One clear impact of coinfection is on $\mathrm{CD}^{+}$cells count: some previous evidence showed that simultaneous infection by these two agents leads to an increase in $\mathrm{CD} 4^{+}$cells count, although without an evident benefit on immune response. This fact can mislead physicians in terms of definition of the right moment to start antiretroviral therapy and/or prophylaxis against opportunistic infections (OI).

Herein, we report two cases of patients with HIV-1/HTLVI coinfection, who developed OI, despite of a high TCD4 ${ }^{+}$ cells count.

\section{Case Report 1}

A 39-year-old black woman, was admitted to the Infectious

Received on 3 May 2009; revised 21 July 2009.

Address for correspondence: Dr. Carlos Brites, MD, PhD. Hospital Universitário Prof. Edgard Santos. Rua João das Botas, SN, 6. ${ }^{\circ}$ andar, Canela. Salvador, Bahia, Brazil. Zip code: 40110-160. Phone: 55-7132354901. Fax: 55-71-32472756. E-mail: crbrites@ufba.br.

The Brazilian Journal of Infectious Diseases 2009;13(4):311-313. (C) 2009 by The Brazilian Journal of Infectious Diseases and Contexto Publishing. All rights reserved.
Disease Clinic at Federal University of Bahia Hospital in January 1999. She had a history of unprotected sexual relations with a intravenous drug abuser. Her main complaints at admission were lower extremities weakness for 3 years with progressive gait disability and urinary incontinence. She also complaint about pruritus associated to disseminated skin lesions for four months. Neurological exam revealed ataxia, hypereflexia, and bilateral Babinski's sign. Diagnostic suspicions were HAM/TSP and Norwegian scabies. Western blot confirmed infections by HIV-1 and HTLV-I. Her first HIV viral load was 35000 copies $/ \mathrm{mm}^{3}$, and TCD4 ${ }^{+}$cells count was 1,517 cells $/ \mathrm{mm}^{3}$.

The skin lesions were successfully treated with Monosulfiram and Ivermectin. Two months later she presented to clinic complaining of dry cough. A chest radiography showed a bilateral peribronchial thickness with hilar nodules. The culture of the bronchoalveolar lavage was positive for Mycobacterium tuberculosis. Therefore, treatment for tuberculosis was initiated with isoniazid, riphampin and pirazinamide.

During the following two years, the lower extremities weakness and gait disability were persistent and progressive. The urinary incontinence remained as well, including an episode of urinary retention complicated by acute renal failure. In March 2001, she presented to the clinic presenting with lethargy, fever, dyspnea and productive cough. A chest radiography was performed and showed bilateral basal infiltrate. The acid-fast bacilli smear from sputum was negative. Then, Pneumocystis jiroveci pneumonia was suspected. It was introduced sulfamethoxazole/trimethoprim, with further complete relief of the symptoms. Her $\mathrm{CD} 4^{+}$cells count at that time was 797 cells $/ \mathrm{mm}^{3}$. She received a Zidovudine plus lamivudine and Efavirenz regimen. After three months the patient complained only about neurological symptoms and had an undetectable viral load.

\section{Case Report 2}

A 58-year-old, asymptomatic white woman, with a diagnosis of HIV infection since 1991, was admitted in the Infectious Disease Outpatient Clinic in October 1994. Her husband had died one year earlier with liver failure due to HCV infection. He was diagnosed as having AIDS, likely acquired through intravenous drug abuse. 
Hypertension was the only significant data in the past medical history. On the physical exam, she had liver enlargement (palpable $4 \mathrm{~cm}$ below of costal margin) and generalized tendinous hypereflexia. She tested positive for HCV and HTLV-I.

She started antiretrovirals in 1999 (Zidovudine+Lamivudine+Indinavir). Her CD4 ${ }^{+}$cells count at that time was 465 . After 1 year, Indinavir was replaced by Nevirapine, due to nausea and vomiting. Her viral load became undetectable since the beginning of treatment.

In December 2005, she was included in the SMART study [8] and randomized to the drug interruption arm. Five months later she presented to the clinic complaining of oral lesions associated to progressive odynophagia and dysphagia. Upper digestive endoscopy showed esophageal candidiasis. At that time, the TCD4 cell count had decreased from 928 to 521 cells/ $\mu \mathrm{L}$ and viral load had increased from undetectable levels to 370,000 copies/mL.

The candidiasis was sucessfully treated with Fluconazole and the antiretroviral therapy was resumed with subsequent control of viremia (less than 50 copies HIV-1 RNA/mL) and further restoration of TCD4 count (last count was 698 cells/ $\mathrm{mm}^{3}$ ),

\section{Discussion}

These two cases demonstrate that coinfection can alter the predictive value of $\mathrm{CD} 4{ }^{+}$cells count as a marker of immune response in patients harboring HIV and HTLV-1.

The clinical impact of HTLV-I/HIV-1 coinfection is uncertain. Evidence that HIV-1 and HTLV-I dual infections may generate unique immune phenotypes and altered HIV-1 disease progression is accumulating [1,2]. Several laboratory and epidemiologic studies suggested that HTLV-I infection increase the cythopatic effects of HIV infection, increase the HIV viral load and accelerate the AIDS clinical progression among coinfected individuals [2,4]. However, other studies do not confirm this hypothesis $[1,5,9,10]$. We have shown that HTLV-I coinfection is associated with a a shorter survival time for HIV- infected patients [7].

Both reported patients developed AIDS defining illness despite of high TCD4 cell count. Another finding that indicates immunodeficiency in the first patient, in spite of her relatively high TCD4 count, was the Norwegian scabies. It has been shown that Norwegian scabies is associated with HTLV I/II infection and the coinfection by HIV-1 seems to be associated with a deeper degree of immunodeficiency, which increases the risk of developing severe forms of scabies and death [7].

In addition, this patient was found to have tuberculosis. A recent Brazilian case-control study [11] has shown that HTLV1 infected individuals are three times more likely to develop tuberculosis than HTLV-1 negative individuals. The authors recommend that patients with HTLV-1 infection should be screened for tuberculosis and those with tuberculosis be screened for HTLV-1 in areas of high prevalence, as northeast of Brazil. Pedral-Sampaio et al, also demonstrated that coinfection increases the mortality rates due to tuberculosis, compared to HIV and HTLV-1 singly-infected patients [12]. Another recent report demonstrated that HTLV-1 alone was not enough to increase the risk of tuberculosis $(\mathrm{OR}=2.41$; $95 \%$ CI 1.26-4.61, $\mathrm{p}=0.008$ ) in a highly endemic country (Guinea Bissau), but HTLV-1 increased such risk among HIV-infected patients [13].

HTLV-I monoinfected patients tend to have higher CD4 ${ }^{+}$ lymphocyte counts than HTLV-I negative controls, possibly due to increased spontaneous proliferation of those cells [1,2]. Probably, a substantial portion of such TCD4 cells population nonspecifically stimulated is dysfunctional, and they do not contribute for an immune response against HIV-1 [1,2,5]. However, it is uncertain how coinfection with HTLV-I affects $\mathrm{CD}^{+}$lymphocyte counts among individuals with HIV infection.[2] This issue is of substantial clinical interest because many clinical decisions in HIV infection are based on the $\mathrm{CD} 4^{+}$lymphocyte count [2].

Studies indicate that there is a dissociation between $\mathrm{CD} 4^{+}$ lymphocyte count and HIV clinical stage, among HIV/HTLV coinfected patients. In Brazil, it was shown that such individuals have higher $\mathrm{CD}^{+}$lymphocyte counts and more advanced clinical disease, in comparison with those singly infected. [2] The higher CD4+ lymphocyte counts associated with coinfection do not seem to provide immunologic benefit, because coinfection is usually associated with both higher $\mathrm{CD}^{+}$counts and more advanced clinical disease $[2,6]$. Dissociation between CD4 count and plasma viral load can also be seen among HIV-infected patients, but usually the CD4 levels reflect the patient's immune status, in contrast with that observed for coinfected individuals.

The results of some studies suggest that the $\mathrm{CD} 4^{+}$count cut off values used to define clinical decisions in HIV infection may not be appropriate in coinfection. It is not known whether the current $\mathrm{CD} 4^{+}$lymphocyte criteria for the initiation of antiretroviral therapy and chemoprophylaxis against opportunistic infections in patients with HIV infection are appropriate for such population [2,5]. A previous study conducted in Bahia provided evidence to suggest that clinicians delay the introduction of antiretroviral therapy for coinfected patients, probably because they are misguided by the artificially high CD4 counts presented by such patients [14].

After starting the antiretroviral treatment in the first patient, her HIV viral load underwent a gradual reduction until undetectable levels. At the same time, $\mathrm{TCD} 4^{+}$cells count had a slightly decline, but remain at normal levels. Despite the relatively high TCD4 count, the patient developed Pneumocystis jiroveci pneumonia, an AIDS- defining illness. The second patient underwent a structured treatment interruption which caused a TCD4 cell count decline and viral load increase. Despite the TCD4 remained relatively high, she developed esophageal candidiasis some months later, also an AIDS-defining illness. Therefore, the high $\mathrm{CD}^{+}$cells count associated with HTLV-I coinfection was not enough to protect patients against the onset of OIs. 
These cases presented clinical evidence to consider treating coinfected patients regardless $\mathrm{CD} 4^{+}$cells counts, when any symptoms are present. Additional studies on the cut off point for this marker are warranted.

\section{References}

1. Beilke M.A., Japa S., Vinson D.G. HTLV-I and HTLV-II virus expression increase with HIV-1 coinfection. J Acquir Immune Defic Syndr Hum Retrovirol 1998;17(5): 391-7

2. Schechter M., Harrison L., Halsey N., et al. Coinfection with human T-cell lymphotropic virus type I and HIV in Brazil. Impact on markers of HIV disease progression. JAMA 1994; 271:353-357.

3. Moreira E.D., Ribeiro T.T., Swanson P., et al. Seroepidemiology of human T-cell lymphotropic virus type I/II in northeastern Brazil. J Acquir Immune Defic Syndr. 1993;6:959-963.

4. Fantry L., Dodging E., Auwaerter P., Lederman H. Immunodeficiency and elevated CD4 lymphocyte counts in two patients coinfected with human immunodeficiency virus and human lymphotropic virus type I. Clin. Infect. Dis. 1995; 21:1446-1448.

5. Beilke M.A., Theall K.P., O’Brien, et al. Clinical outcomes and disease progression among patients coinfected with HIV and human T lymphotropic virus types 1 and 2. Clin Infect Dis. 2004 Jul 15;39(2):256-63.

6. Cesaire R., Dehee A., Lezin A., et al. Quantification of HTLV type I and HIV type I DNA load in coinfected patients: HIV type 1 infection does not alter HTLV type I proviral amount in the peripheral blood compartment. AIDS Res Hum Retroviruses 2001;17(9):799-805
7. Brites C., Weyll M., Pedroso C., Badaro R. Severe and Norwegian scabies are strongly associated with retroviral (HIV-1/HTLV1)infection in Bahia, Brazil. AIDS. 2002 Jun 14;16(9):1292-3.

8. Strategies for Management of Antiretroviral Therapy (SMART) Study Group, El-Sadr W.M., Lundgren J.D., Neaton J.D., et al. CD4+ count-guided interruption of antiretroviral treatment. N Engl J Med. 2006 Nov 30;355(22):2283-96.

9. Harrison L., Quinn T., Schechter M. Human T cell lymphotropic virus type I does not increase human immunodeficiency virus viral load in vivo. J. Infect. Dis. 1997; 175:438-440.

10. Hershow R.C., Galai N., Fukuda K., et al. An international collaborative study of the effects of coinfection with human T-lymphotropic virus type II on human immunodeficiency virus type I disease progression in injection drug users. J Infect Dis 1996;174:309-17

11. Marinho J., Galvao-Castro B., Rodrigues L.C., Barreto M.L. Increased risk of tuberculosis with human T-lymphotropic virus1 infection: a case-control study. J Acquir Immune Defic Syndr. 2005 Dec 15;40(5):625-8.

12. Pedral-Sampaio D.B., Martins Netto E., Pedrosa C., Brites C., Duarte M., Harrington W. Jr.Co-Infection of Tuberculosis and HIV/HTLV Retroviruses: Frequency and Prognosis Among Patients Admitted in a Brazilian Hospital. Braz J Infect Dis. 1997 Mar;1(1):31-35.

13. Norrgren HR, Bamba S, Larsen O, et al. Increased prevalence of HTLV-1 in patients with pulmonary tuberculosis coinfected with HIV, but not in HIV-negative patients with tuberculosis. J Acquir Immune Defic Syndr, 2008 15;48(5):607-10.

14. Brites C, Goyanna F, França LG, Netto EM, Pedral-Sampaio D, Badaró R, Harrington Jr. W. Co-infection by HTLV-I/II increases the risk of strongyloidiasis and may lead to a delayed introduction of antiretroviral therapy for HIV infected patients. 11th Conference on Retroviruses and Opportunistic Infections (CROI), February 8-11, 2004, San Francisco, CA (Abst. O-38). 